\title{
Patterns of wasting among pregnant and lactating women in Uganda, 2015-2018: analysis of Nutrition surveillance data
}

Irene Byakatonda Kyamwine ${ }^{1 *}$, Samalie Namukose², Yvette Wibabara1', Lilian Bulage', Benon Kwesiga', Alex Riolexus Ario ${ }^{1}$ and Julie R. Harris ${ }^{3}$

\begin{abstract}
Background: Maternal nutrition is closely linked to the survival and development of children during the first 1000 days of life. Maternal wasting, a measure of malnutrition, is measured using the mid-upper arm circumference. However, in 2019, the rate and distribution of wasting among pregnant and lactating women was not known. We described annual trends and distribution of wasting among pregnant and lactating women (PLW), Uganda, 20152018, to inform programming on targeted nutritional interventions.

Methods: We analyzed nutrition surveillance data from the District Health Information System for all PLW from 2015 to 2018. We used the World Health Organization standard thresholds to determine wasting among PLW by year and region, drawing choropleth maps to demonstrate the geographic distribution of wasting among PLW. We used logistic regression to assess wasting trends.

Results: During 2015-2018, 268,636 PLW were wasted (prevalence $=5.5 \%$ ). Of the 15 regions of Uganda, Karamoja (prevalence $=21 \%)$ and Lango (prevalence $=17 \%)$ registered the highest prevalence while Toro (prevalence $=2.7 \%)$ and Kigezi (prevalence $=2.0 \%$ ) registered the lowest prevalence. The national annual prevalence of wasting among PLW declined by 31\% from 2015 to $2018(\mathrm{OR}=0.69, p<0.001)$. Regions in the north had increasing trends of wasting over the period [Lango $(\mathrm{OR}=1.6, p<0.001)$ and Acholi $(\mathrm{OR}=1.2, p<0.001)$ ], as did regions in the east [(Bugisu (OR $=3.4, p<0.001)$, Bukedi $(\mathrm{OR}=1.4, p<0.001)$, and Busoga $(\mathrm{OR}=1.3, p<0.001)]$. The other 11 regions showed declines.

Conclusion: The trend of wasting among PLW nationally declined during the study period. Lango and Acholi regions, both of which were experiencing a nutrition state of emergency during this period, had both high and rising rates of wasting, as did the Karamoja region, which experienced the highest wasting rates. We recommended that the Ministry of Health increases its focus on nutrition monitoring for PLW and conduct an analysis to clearly identify the factors underlying malnutrition specific for PLW in these regions.
\end{abstract}

Keywords: Wasting, Pregnant, Lactating, Women, Uganda

\footnotetext{
* Correspondence: ikyamwine@musph.ac.ug

'Uganda Public Health Fellowship Program, Ministry of Health, Kampala, Uganda

Full list of author information is available at the end of the article
}

C C The Author(s). 2021 Open Access This article is licensed under a Creative Commons Attribution 4.0 International License, which permits use, sharing, adaptation, distribution and reproduction in any medium or format, as long as you give appropriate credit to the original author(s) and the source, provide a link to the Creative Commons licence, and indicate if changes were made. The images or other third party material in this article are included in the article's Creative Commons licence, unless indicated otherwise in a credit line to the material. If material is not included in the article's Creative Commons licence and your intended use is not permitted by statutory regulation or exceeds the permitted use, you will need to obtain permission directly from the copyright holder. To view a copy of this licence, visit http://creativecommons.org/licenses/by/4.0/ The Creative Commons Public Domain Dedication waiver (http://creativecommons.org/publicdomain/zero/1.0/) applies to the data made available in this article, unless otherwise stated in a credit line to the data. 


\section{Background}

Malnutrition refers to deficiencies, excesses, or imbalances in a person's intake of energy and/or nutrients. It includes both undernutrition, which covers stunting, wasting, and micronutrient deficiencies, and overnutrition [1]. Wasting refers to low weight-for-height and usually indicates a recent weight loss; if not addressed promptly, wasting is often associated with morbidity and mortality among both adults and children [2, 3].

Adequate nutrition is crucial for the survival, health, and development of mothers and their children [4, 5]. During pregnancy and lactation, there is an increased demand for energy, protein, and essential micronutrients to maintain not only the mother's but also the child's health and development [6, 7]. Maternal malnutrition predisposes mothers to maternal complications, and children to fetal birth defects, low birth weight, restricted physical and mental potential, and fetal or newborn mortality [8] and accounts for approximately $20 \%$ of childhood stunting [9]. A malnourished mother is more likely to deliver a malnourished baby, who will grow into a malnourished adult [8]. Because of this, ending malnutrition among pregnant and lactating women is a critical factor in breaking the cycle of malnutrition in the population.

Despite a decline in the prevalence of malnutrition globally, undernutrition remains a challenge of public health concern worldwide. In 2016, the global prevalence of underweight (9.7\%) and anemia (32.8\%) among women of reproductive age (15-49years) were still above the World Health Assembly (WHA) 2025 targets of $5 \%$ for underweight and $15 \%$ for anemia [10-12]. In Uganda in 2016, the prevalence of underweight and anemia among women of reproductive age were 9 and $32 \%$, respectively $[13,14]$.

In response to the National Development Plan (20102015) objective of improved nutrition in the Ugandan population, Uganda began scaling up the Nutrition Strategy with a focus on the first 1000 days of life, which refers to the period of time (for both the mother and the fetus/infant) from conception to 2 years of age $[15,16]$. In 2011, Uganda developed a national nutrition strategy (Uganda Nutrition Action Plan 1, or UNAP 1) aimed at breaking the cycle of malnutrition and improving the livelihood of Ugandans [16].

During the 5 years of implementing the strategy (2011-2016), the prevalence of thinness (wasting) among non-pregnant or lactating women of reproductive age in Uganda declined from 11 to $9 \%$. During the same period, wasting among children also declined from 5 to $4 \%$ and stunting declined from 33 to $29 \%$ [13]. However, wasting specific to pregnant or lactating women (PLW) in Uganda has not yet been evaluated. Since the strategy focuses on the first 1000 days of life understanding nutrition state of pregnant and lactating women who make up the largest part of this period is crucial for programing. We estimated the prevalence and described the trends and geographical distribution of wasting among PLW in Uganda during 2015-2018 to inform targeted programming to break the cycle of malnutrition.

\section{Methods}

\section{Study setting}

Our study utilized data collected from all the 15 subregions of Uganda, with 135 districts [17, 18]. In 2019, Uganda had an estimated population of 40 million persons [19].

\section{Study design}

We conducted a retrospective descriptive analysis of nutrition surveillance data from the District Health Information Software 2 (DHIS2), which are submitted quarterly from all the health facilities in Uganda. Our study focused on wasting because it accounts for higher proportions of intrauterine growth retardation (IUGR) and impaired fetal development, which carry lifelong adverse effects in children [5, 20].

\section{Nutrition surveillance system in Uganda, 2015-2018}

As per the Uganda Ministry of Health $(\mathrm{MoH})$, a case of wasting in a PLW is defined as a mid-upper arm circumference $(M U A C)$ in the red $(<19.0 \mathrm{~cm})$ or yellow $(\geq 19.0$ to $<22.0 \mathrm{~cm}$ ) zone on the MUAC tape [21]. The $\mathrm{MoH}$ captures nutrition data through the Health Management Information System (HMIS). These data are generated from various registers at the key health facility contact points, including integrated nutrition registers, outpatient department registers, antenatal clinic registers (ANC), postnatal clinic registers, immunization/young child clinics, maternity wards, HIV clinics, and inpatient wards and are collated in HMIS form 106a, after which they are entered into DHIS2. The MoH summarizes these data on a monthly, quarterly, and annual basis and disseminates the findings to various stakeholders.

\section{Study variables and data abstraction}

We extracted data from DHIS2 from 2015 to 2018. The variables obtained were PLW assessed for wasting using MUAC, PLW with yellow MUAC, and PLW with red MUAC. We also extracted data on the reporting rates of the HMIS 106a form for the same period to estimate rates of under-reporting.

\section{Data management and analysis}

We extracted nutrition data from DHIS directly into Microsoft Excel for cleaning. We excluded all districts with more malnourished PLW than those seen at ANC 
from the analysis. We imported the data into Epi-Info version 7 for analysis. We calculated the prevalence of wasting (moderate and severe) at national and regional levels, disaggregated by year. The numerator was all wasted PLW as measured by MUAC. The number of PLW assessed for wasting using MUAC within the analysis period was used as the denominator to calculate prevalence. We used the WHO categorization of wasting by prevalence which considers $<5 \%$ acceptable, $5-9 \%$ poor, $10-14 \%$ serious and $\geq 15 \%$ critical to guide interventions $[22,23]$.. These thresholds are used in decisionmaking to determine the need for different types of feeding programmes. We generated trends nationally and regionally; drew line graphs to demonstrate the trends; and used logistic regression to test for significance of the trends. We used quantum geographic information system (QGIS) version 2.8.2 to generate maps to demonstrate the geographical distribution of wasting among PLW by region.

\section{Results}

Prevalence of wasting among pregnant and lactating women, overall and by region, Uganda, 2015-2018

Of the 4,848,873 pregnant and lactating women assessed for wasting over the study period, 268,636 (5.5\%) were wasted. The median prevalence was $6.8 \%$. Regions in the northern part of the country had the highest overall prevalence of wasting, while those in the regions in the western part had the lowest overall prevalence (Fig. 1).

According to the WHO classification of malnutrition, Karamoja and Lango were in the critical malnutrition category (prevalence $>15 \%$ ) while Acholi was in the serious malnutrition category (Fig. 1).

Trends of wasting among pregnant and lactating women, overall and by region, Uganda, 2015-2018

The national annual prevalence of wasting among pregnant and lactating women declined by 31\% from 2015 to 2018 (OR $=0.69, p<0.001) \quad($ Table 1$)$. The district reporting rate for nutrition was nearly complete across all years $(98-100 \%)$.

The prevalence of wasting among pregnant and lactating women increased from 2015 to 2018 in Bugisu $(\mathrm{OR}=3.4, p<0.001)$, Lango $(\mathrm{OR}=1.6, p<0.001)$, Bukedi (1.4, $\mathrm{p}<0.001)$, Busoga $(\mathrm{OR}=1.3, p<0.001)$, and Acholi $(\mathrm{OR}=1.2, p<0.001)$ regions, while the rest of the regions had declining trend (Fig. 2).

\section{Discussion}

Analysis of surveillance data from 2015 to 2018 showed a decreasing trend nationally in wasting among pregnant and lactating women. Several regions in the north had increasing trends of wasting, while those in the western and southern parts of Uganda had declined. Two

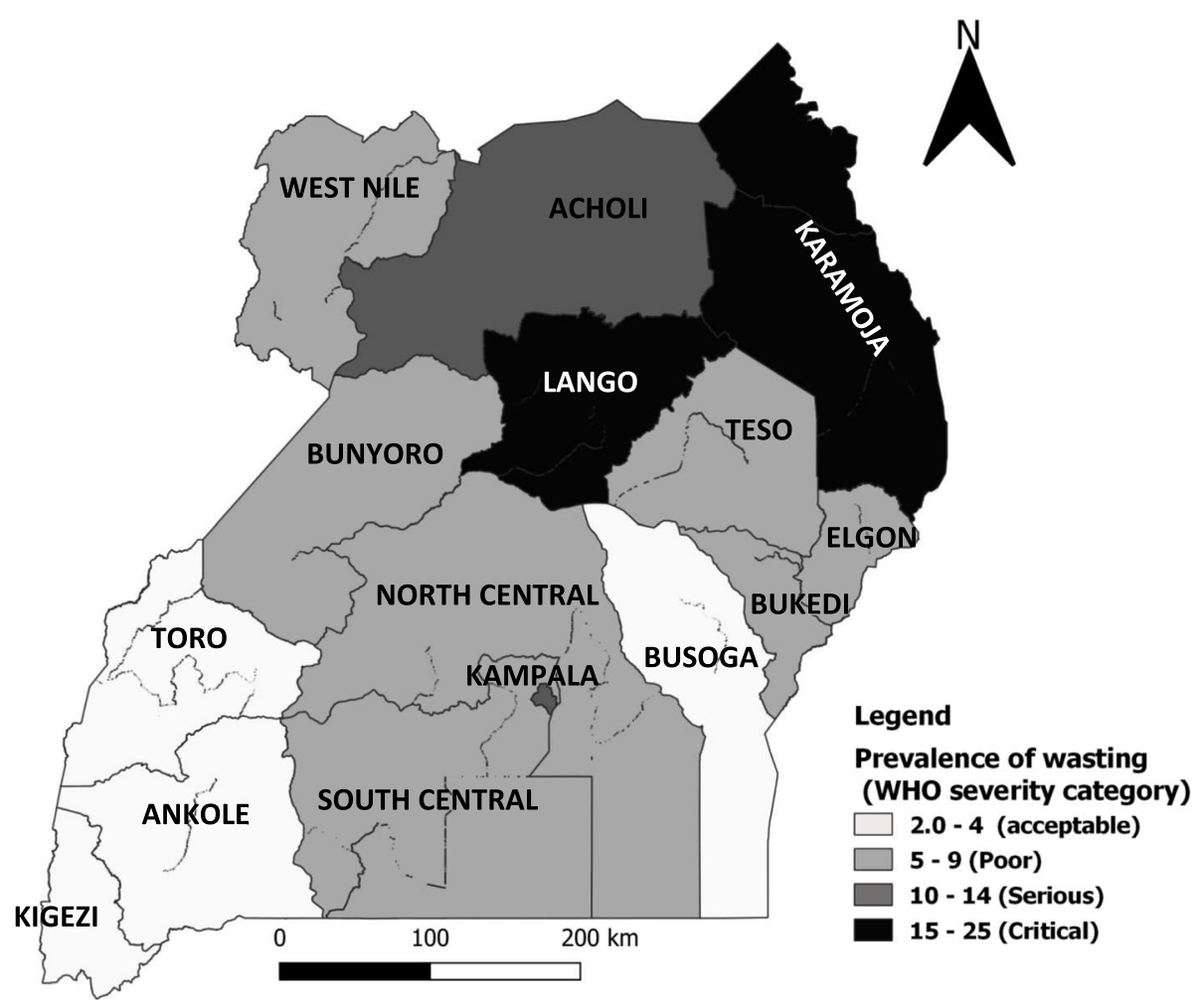

Fig. 1 Prevalence of wasting among pregnant and lactating women, Uganda, 2015-2018 
Table 1 Regional trends in prevalence of malnutrition among pregnant and lactating women, Uganda 2015-2018

\begin{tabular}{llllll}
\hline Region & \multicolumn{3}{l}{ Prevalence (\%) } & OR (95\% CI) \\
\cline { 2 - 5 } & $\mathbf{2 0 1 5}$ & $\mathbf{2 0 1 6}$ & $\mathbf{2 0 1 7}$ & $\mathbf{2 0 1 8}$ & \\
\hline Acholi & 1.4 & 7.3 & 16 & 9.6 & $1.2(1.2-1.2)$ \\
Ankole & 24 & 4.5 & 2.8 & 1.7 & $0.48(0.47-0.49)$ \\
Bukedi & 6.0 & 1.6 & 0.8 & 11 & $1.4(1.3-1.4)$ \\
Bunyoro & 7.3 & 1.3 & 3.3 & 6.3 & $0.95(0.92-0.97)$ \\
Busoga & 29 & 0.7 & 11 & 6.1 & $1.3(1.3-1.3)$ \\
Bugisu & 1.1 & 0.7 & 5.6 & 4.0 & $3.4(3.2-3.6)$ \\
Kampala & 77 & 15 & 4.1 & 1.1 & $0.13(0.13-0.14)$ \\
Karamoja & 70 & 5 & 16 & 17 & $0.55(0.54-0.55)$ \\
Kigezi & 1.5 & 2.8 & 3.2 & 0.6 & $0.66(0.65-0.67)$ \\
Lango & 11 & 14 & 8.9 & 28 & $1.6(1.6-1.7)$ \\
North Central & 3.1 & 5.6 & 5.3 & 4.0 & $0.88(0.86-0.9)$ \\
South Central & 0.9 & 14 & 5 & 5.8 & $0.74(0.73-0.75)$ \\
Teso & 6.9 & 13 & 6.4 & 6.2 & $0.81(0.80-0.82)$ \\
Toro & 4.2 & 7.8 & 1.1 & 1.6 & $0.54(0.53-0.54)$ \\
West Nile & 4.4 & 7.5 & 3.4 & 4.9 & $0.92(0.9-0.93)$ \\
National & $\mathbf{4 . 5}$ & $\mathbf{4 . 9}$ & $\mathbf{6 . 4}$ & $\mathbf{1 7}$ & $0.69(0.69-0.69)$ \\
\hline
\end{tabular}

adjoining regions in the north, Karamoja and Lango, had critical levels of malnutrition and a third had serious malnutrition.

Causes of malnutrition are known to be multifactorial in nature. As a result, strategies such as the Uganda Multi-sectoral Food Security and Nutrition Project (UMFSNP), implemented in 2015 in 15 districts of Uganda [24], have been enacted to address several of these causes jointly. The target population for UMFSNP includes pregnant and lactating women, children under 2 years, and parent groups participating in nutrition-promoting activities. The overall decline in the prevalence of wasting during the study period is likely linked to this approach, at least in part. Regions in which this plan was implemented, including Ankole, Busoga, Kigezi, Tooro, and West Nile, showed declining trends in wasting in this analysis. The possible success of the UMFSNP suggests a need to scale up the implementation of the multisectoral program to additional districts.

Despite the overall decline in the prevalence of wasting countrywide, disaggregated data showed that some regions, especially those in the north, still have high levels of wasting among PLW. Specifically, the northern regions of Karamoja, Lango, and Acholi were found to have the highest prevalence of wasting in this evaluation. These regions have long had prolonged droughts, insecurity, livestock diseases, and flooding which have crippled crop and livestock production [25]; in addition, they consistently experience high levels of poverty and often score poorly across multiple health indicators [13, $26,27]$. Karamoja region is mainly occupied by nomadic pastoralists, who typically do not settle in a single place to cultivate crops. This further deepens the food insecurity and also hinders access to preventive measures and treatment of major illnesses that cause or result from malnutrition [25]. The introduction of modern and innovative farming methods for the northern regions, such as use of drought-resistant seeds and mechanization of farming, could help reduce the food insecurity in these regions and mitigate malnutrition [28].

Despite having the highest prevalence of wasting in our evaluation, the Karamoja region did register a decline, possibly due to the ongoing food aid it has received for over 40 years $[29,30]$. While fixed clinics exist in the region, the establishment of supplemental mobile clinics to provide health and nutrition services within Karamoja and surrounding regions might help provide the essential nutrition interventions. This approach has improved health services among other nomadic populations in Kenya and other parts of Africa $[31,32]$. Intensification of supplementary and therapeutic feeding programs for pregnant and lactating women is also recommended [23]. Nutrition programs targeting households rather than individuals might improve outcomes, as food in this region is shared within households even when delivered to a single targeted individual, such as a pregnant or lactating mother [33].

Bugisu region, located in eastern Uganda, showed an increase in wasting during the evaluation period, reaching the 'serious' severity level in 2018. This region is subject to recurrent natural disasters, such as mudslides, and floods, that cause crop loss; the most recent of these events occurred during December 2019 [34-36]. These types of natural disasters are known to be associated with subsequent malnutrition [37-39]. Implementation of assistance in form of food and/or cash transfers could help in preventing malnutrition in such emergencies and should be evaluated as a possible policy option. Such interventions have helped improve the nutrition outcomes in similar contexts. Studies in multiple countries have shown that cash transfers alone or in combination with other interventions prevented malnutrition and improved outcomes [40-42].

\section{Study limitation}

It is likely that some PLW were counted more than once due to repeat visits to facilities; this may have led to an overestimation of the burden of wasting in our evaluation. Alternatively, the low HMIS reporting rates, especially in 2018, may have led to an underestimation of wasting. 

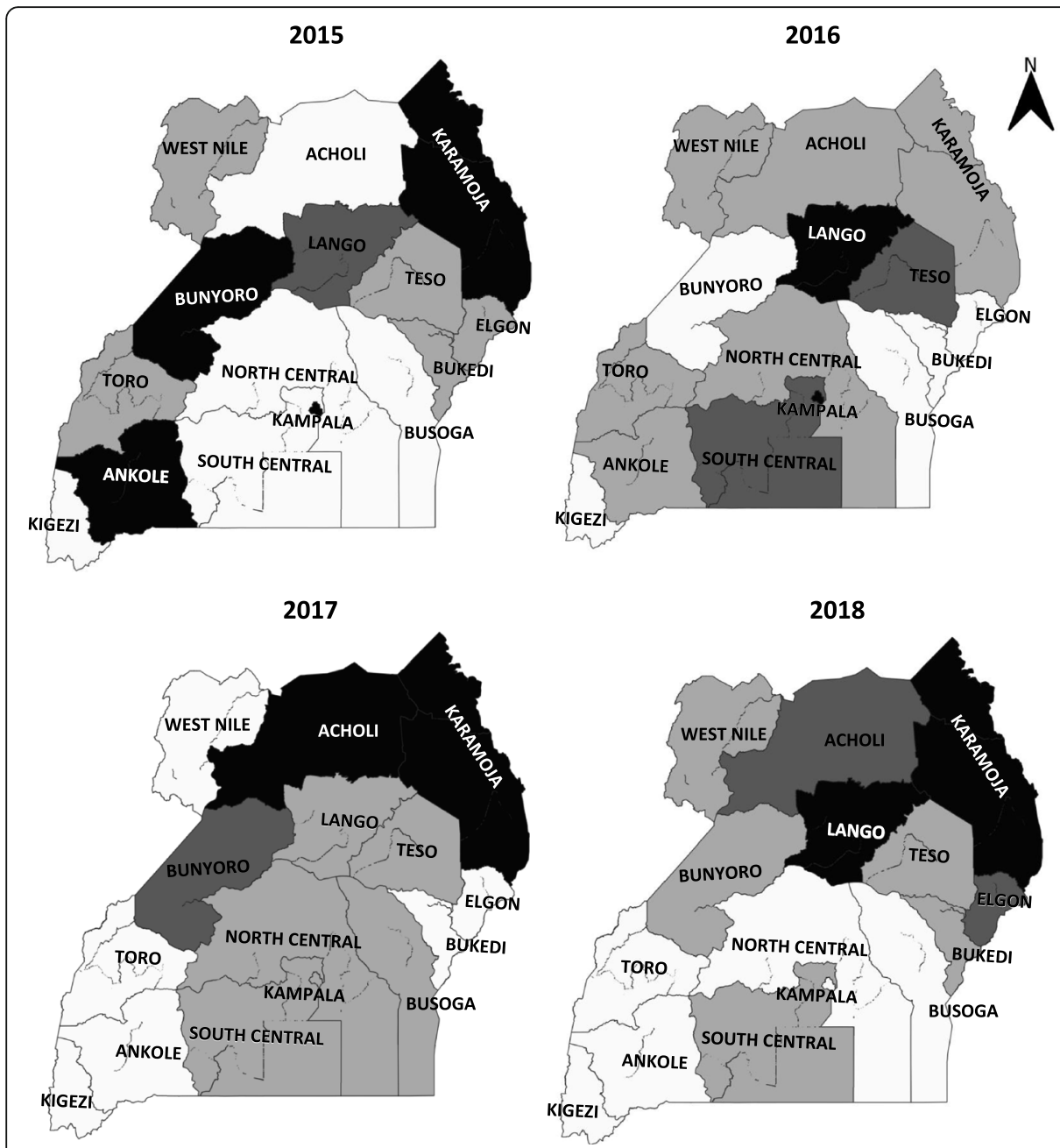

\section{Legend}

Prevalence of wasting (WHO severity category)

0.9 - 4 (Acceptable)

5 - 9 (Poor)

10 - 14 (Serious)

15 - 80 (Critical)

Fig. 2 Regional trends in prevalence of wasting among pregnant and lactating women, Uganda 2015-2018

\section{Conclusion and recommendations}

The national trend of wasting among pregnant and lactating women declined during 2015-2018. Lango and the Acholi regions had high and rising rates of wasting. Karamoja and Lango regions experienced critical malnutrition, while Acholi region experienced serious malnutrition. We recommended that the Ministry of Health sustains interventions in place for malnutrition with special attention to Karamoja, Lango, and Acholi regions. A causal analysis to clearly understand the factors underlying malnutrition among PLW in these regions should be conducted and consideration given to implementing alternative approaches to addressing malnutrition in locations with chronically high rates.

\section{Abbreviations}

ANC: Antenatal care; CDC: US Centers for Disease Control and Prevention; DHIS2: District Health Information Software version 2; HMIS: Health

Management Information System; MoH: Ministry of Health; MUAC: Mid upper arm circumference; OR: Odds ratio; PLW: Pregnant and lactating women; UBOS: Uganda bureau of statistics; UMFSNP: Uganda Multi-sectoral Food
Security and Nutrition Project; WHA: World Health Assembly; WHO: World Health Organization

\section{Acknowledgements}

We appreciate the Ministry of Health for permission to access the National health information database. We thank the US-CDC for supporting the Uganda Public Health Fellowship Program activities and the Nutrition Division for the technical support rendered through the whole process.

\section{Authors' contributions}

IBK and NS were involved in the design of the project. IBK, YW, BK and LB were involved in the data analysis and all were involved in report writing. IBK, LB, BK, ARA and JH had primary responsibility for final content. IBK drafted the manuscript and all other authors (LB, NS, JH and ARA) participated substantially in the writing, and read and approved the final manuscript.

\section{Funding}

This project was supported by the President's Emergency Plan for AIDS Relief (PEPFAR) through the US Centers for Disease Control and Prevention

Cooperative Agreement number GH001353-01 through Makerere University School of Public Health to the Uganda Public Health Fellowship Program, $\mathrm{MOH}$. Its contents are solely the responsibility of the authors and do not necessarily represent the official views of the US Centers for Disease Control and Prevention, the Department of Health and Human Services, Makerere 
University School of Public Health, or the $\mathrm{MOH}$. The staff of the funding body provided technical guidance in the design of the study, ethical clearance and collection, analysis, and interpretation of data and in writing the manuscript.

\section{Availability of data and materials}

The datasets upon which our findings are based belong to the Uganda Public Health Fellowship Program. For confidentiality reasons, the datasets are not publicly available. However, the data sets can be availed upon reasonable request from the corresponding author and with permission from the Uganda Public Health Fellowship Program.

\section{Declarations}

\section{Ethics approval and consent to participate}

We sought permission to use the data from the $\mathrm{MoH}$. The US Centers for Disease Control and Prevention (CDC) provided a non-research determination for this project. The date used in this analysis was aggregated national surveillance data that did not have individual patient details; hence there was no requirement for patient informed consent. We stored data in password-protected computers and only the study team had access to the data.

\section{Consent for publication}

Not applicable.

\section{Competing interests}

The authors declare that they had no competing interests.

\section{Author details}

'Uganda Public Health Fellowship Program, Ministry of Health, Kampala, Uganda. ${ }^{2}$ Nutrition Division, Ministry of Health, Kampala, Uganda. ${ }^{3}$ Workforce and Institute Development Branch, Division of Global Health Protection, Center for Global Health, US Centers for Disease Control and Prevention, Kampala, Uganda.

\section{Received: 5 February 2021 Accepted: 29 August 2021}

\section{Published online: 14 October 2021}

References

1. World Health Organization (WHO). Malnutrition; 2018. p. 1.

2. WHO, UNICEF, WFP. Global Nutrition Targets 2025: Wasting Policy Brief (WHO/NMH/NHD/14.8); 2014. p. 8.

3. Measuring malnutrition: Individual assessment technical-notes.pdf [Internet]. [cited 2021 Jan 8]. Available from: https://www.ennonline.net/attachments/1 054/m6-measuring-malnutrition-individual-assessment-technical-notes.pdf

4. Wu G, Bazer F, Cudd T, Meininger C. Recent advances in nutritional sciences-maternal Nutrition and fetal development. Nutr. 2004;13:2169-72.

5. Vir SC. Improving women's nutrition imperative for rapid reduction of childhood stunting in South Asia: coupling of nutrition specific interventions with nutrition sensitive measures essential. Matern Child Nutr. 2016;12:72-90. https://doi.org/10.1111/mcn.12255.

6. Kominiarek MA, Rajan P. Nutrition recommendations in pregnancy and lactation. Med Clin North Am. 2016;100(6):1199-215. https://doi.org/10.1016/ j.mcna.2016.06.004

7. Improving Nutrition and Health for Pregnant and Lactating Women [Internet]. SUN. 2016 [cited 2021 Jul 14]. Available from: https://sca lingupnutrition.org/news/improving-nutrition-and-health-for-pregnant-andlactating-women/

8. LINKAGES, Child Survival Collaborations and Resources (CORE) Nutrition Wprking Group. Maternal Nutrition during Pregnancy and Lactation. 2004. Available from: https://coregroup.org/wp-content/uploads/2017/09/Materna I-Nutrition-During-Pregnancy-and-Lactation.pdf.

9. World Health Organization. Global Nutrition Target 2025 Stunting Policy Brief. 2012;(9)

10. Hawkes C. 2018 Global Nutrition Report Expert Group of the Global Nutrition Report. 2018;(November).

11. World Health Organization (WHO). Global Nutrition Targets 2025 Policy Brief Series. 2014

12. World Health Organization, 1000 days. Global Nutrition Targets 2025 Policy Brief Series 2014
13. Government of Uganda, Uganda Bureau of Statistics, The DHS Program ICF. Uganda Demographic and Health Survey; 2016. p. 2018.

14. Nankinga O, Aguta D. Determinants of Anemia among women in Uganda: further analysis of the Uganda demographic and health surveys. BMC Public Health. 2019;19(1):1757. https://doi.org/10.1186/s12889-019-8114-1.

15. uganda-national_development_plan.pdf [Internet]. [cited 2020 May 13]. Available from: https://www.adaptation-undp.org/sites/default/files/downloa ds/uganda-national_development_plan.pdf.

16. Government of Uganda. Uganda Nutrition Action Plan 2011 -2016Scaling Up Multi-Sectoral Efforts to Establish a Strong Nutrition Foundation for Uganda's Development. 2011. Available from: https://www.health.go.ug/ docs/UNAP_11_16.pdf.

17. Uganda Bureau of Statistics. Population Projections By District, 2015 to 2021. 2020

18. Explore Statistics - Page 20 - Uganda Bureau of Statistics [Internet]. [cited 2020 May 10]. Available from: https://www.ubos.org/explore-statistics/20/

19. Uganda Bureau of Statistics (UBOS). Population Projections 2015. 2014

20. Bale JR, Stoll BJ, Lucas AO. Improving Birth Outcomes: Meeting the Challenge in the Developing World; 2003. p. 204.

21. Uganda Ministry of Health. Health Management Information Information System For Nutrition; 2010. p. 0-35. September

22. Food and Agriculture Organization, European Union. Nutritional Status Assessment and Analysis Nutritional Status Indicators Learner Notes. 2007.

23. De Onis M, Borghi E, Arimond M, Webb P, Croft T, Saha K, et al. Prevalence thresholds for wasting, overweight and stunting in children under 5 years. Public Health Nutr. 2019;22(1):175-9. https://doi.org/10.1017/S136898001 8002434.

24. Uganda Multi-Sector Food Security and Nutrition project - Ministry of Agriculture, Animal Industry and Fisheries [Internet]. [cited 2020 Jun 4]. Available from: https://www.agriculture.go.ug/uganda-multi-sector-foodsecurity-and-nutrition-project/

25. Action Against Hunger. Nutrition Surveillance Data Analysis, Karamoja, Uganda December 2009 - May 2012. 2013;(August).

26. Food and Nutrition Technical Assistance II Project (FANTA-2). The Analysis of the Nutrition Situation in Uganda; 2010. p. 94. May

27. Uganda Bureau of Statistics. Uganda Bureau of Statistics Statistical Abstract 2018 [Internet]. 2019 [cited 2021 Jan 13]. Available from: http://library.health. go.ug/publications/statistics/uganda-bureau-statistics-statistical-abstract-2018

28. John Ruane. Proceedings of the International Symposium on Agricultural Innovation for Family Farmers: Unlocking the Potential of Agricultural Innovation to Achieve the Sustainable Development Goals.

29. Karamoja and Northern Ugand, a Comparative analysis of livelihood recovery in the post-conflict periods November 2019 [Internet]. [cited 2020 Jun 8]. Available from: http://www.fao.org/3/ca5760en/CA5760EN.pdf

30. Weaning Karamoja off food aid - Uganda [Internet]. ReliefWeb. [cited 2020 Jun 8]. Available from: https://reliefweb.int/report/uganda/weaning-kara moja-food-aid

31. Jillo JA, Ofware PO, Njuguna S, Mwaura-Tenambergen W. Effectiveness of Ng'adakarin Bamocha model in improving access to ante-natal and delivery services among nomadic pastoralist communities of Turkana West and Turkana North Sub-Counties of Kenya. Pan Afr Med J. 2015 [cited 2020 Jun 8];20. Available from: http://www.panafrican-med-journal.com/content/a rticle/20/403/full/

32. Ali M, Cordero JP, Khan F, Folz R. 'Leaving no one behind': a scoping review on the provision of sexual and reproductive health care to nomadic populations. BMC Womens Health. 2019;19(1):161.

33. Gebre B, Biadgilign S, Taddese Z, Legesse T, Letebo M. Determinants of malnutrition among pregnant and lactating women under humanitarian setting in Ethiopia. BMC Nutr. 2018;4(1):1-8.

34. Office of the Prime Minister. National Policy and Implemetation on DRR. 2011;

35. Mayega RW, Tumuhamye N, Atuyambe L, Bua G, Ssentongo J, Bazeyo W. Qualitative Assessment of Resilience to the Effects of Climate Variability in the Three Communities in Uganda; 2015. p. 58. July

36. Floods, landslides: Gov't speaks out on disaster situation - Uganda | ReliefWeb [Internet]. [cited 2020 Aug 17]. Available from: https://reliefweb. int/report/uganda/floods-landslides-govt-speaks-out-disaster-situation

37. Press D. Impact of disasters on child stunting in Nepal; 2016. p. 113-27.

38. Rodriguez-llanes JM, Ranjan-dash S, Degomme O, Mukhopadhyay A, Guhasapir D. Child malnutrition and recurrent flooding in rural eastern India: a community-based survey; 2011. p. 1-8. 
39. Datar A, Liu J, Linnemayr S, Stecher C. The Impact of Natural Disasters on Child Health and Investments in Rural India. 2014;76(1):83-91.

40. Langendorf C, Roederer T, de Pee S, Brown D, Doyon S, Mamaty A-A, et al. Preventing Acute Malnutrition among Young Children in Crises: A

Prospective Intervention Study in Niger. PLoS Med [Internet]. 2014 Sep 2 [cited 2020 Sep 5];11(9). Available from: https://www.ncbi.nlm.nih.gov/ pmc/articles/PMC4152259/

41. Bliss J, Golden K, Bourahla L, Stoltzfus R, Pelletier D. An emergency cash transfer program promotes weight gain and reduces acute malnutrition risk among children 6-24 months old during a food crisis in Niger. J Glob Health [Internet]. [cited 2020 Sep 5];8(1). Available from: https://www.ncbi. nlm.nih.gov/pmc/articles/PMC5825977/

42. Doocy S, Busingye M, Lyles E, Colantouni E, Aidam B, Ebulu G, et al. Cash and voucher assistance and children's nutrition status in Somalia. Matern Child Nutr [Internet]. 2020 Jul [cited 2020 Sep 18];16(3). Available from: https://www.ncbi.nlm.nih.gov/pmc/articles/PMC7296788/

\section{Publisher's Note}

Springer Nature remains neutral with regard to jurisdictional claims in published maps and institutional affiliations.

Ready to submit your research? Choose BMC and benefit from:

- fast, convenient online submission

- thorough peer review by experienced researchers in your field

- rapid publication on acceptance

- support for research data, including large and complex data types

- gold Open Access which fosters wider collaboration and increased citations

- maximum visibility for your research: over $100 \mathrm{M}$ website views per year

At BMC, research is always in progress.

Learn more biomedcentral.com/submissions 